\title{
Editorial
}

\section{Tiempo protegido de investigación para mejorar el liderazgo profesional}

\author{
Herney Andrés García-Perdomo ${ }^{1}$ \\ ${ }^{1}$ Departamento de Cirugía/Urología. Escuela de Medicina. \\ Universidad del Valle. Cali, Colombia.
}

Urol Colomb 2019;28:269-270.

El entrenamiento de una especialidad quirúrgica se ha centrado en el conocimiento, el cuidado de los pacientes, la obtención de habilidades de procedimiento y la enseñanza, lo que lleva a poco tiempo para investigar. Algunos de los cirujanos y profesores creen que este es el tema más importante a cubrir ya que el cirujano más capacitado, será el más experto en el área elegida. No obstante, algunos estudios y declaraciones han descrito una nueva era para un científico quirúrgico lo cual podría mejorar el rendimiento en el área siempre que se innove y aplique en la especialidad quirúrgica ${ }^{1,2}$.

La naturaleza de la capacitación quirúrgica coloca a los cirujanos / urólogos en una desventaja relativa para el éxito académico, ya que los programas de segunda especialidad otorgan la experiencia en investigación pero no así en la capacitación de la especialidad primaria ${ }^{3}$. En los países desarrollados, los médicos pueden obtener capacitación en investigación antes de comenzar su capacitación especializada, y a veces están involucrados en el proceso de subvención y la oportunidad de establecer una línea de investigación con algunos mentores. Sin embargo, esto no sucede en países en vía de desarrollo ${ }^{4}$.

Por otro lado, hace muchos años, las empresas comerciales comenzaron a controlar la investigación en medicina, y el apoyo financiero (de diferentes partes) fue mínimo ${ }^{5}$. El efecto de estos elementos influye en la disminución del número de médicos (cirujanos) involucrados en la investigación y la disminución de la investigación quirúrgica. Esto nos lleva a entrenar a nuestros futuros científicos quirúrgicos para iluminar la llama de la investigación en nuestra área ${ }^{1}$.

En este caso, nutrir la carrera académica protegiendo el tiempo para la investigación podría beneficiarse de tener una vida profesional exitosa. Hoy en día, los jóvenes urólogos enfrentan un escenario académico hipercompetitivo; por lo tanto, es de vital importancia proteger la investigación de la asistencia, la docencia y la administración. Los residentes deben tener tiempo para leer $\mathrm{y}$ comprender críticamente la literatura publicada, asistir a conferencias de metodología, discutir con colegas, realizar y supervisar experimentos de campo, analizar datos, gestionar requisitos administrativos, escribir solicitudes de subvención convincentes y escribir manuscritos, entre muchas otras tareas de investigación esenciales durante su entrenamiento ${ }^{6}$.

Tener un tiempo protegido es vital para el urólogo joven y el residente para explorar intereses académicos como: 1) Decidir si la investigación es impresionante; 2) El tipo de investigación (básica, traslacional, clínica o combinada), 3) Obtener un enfoque particular y 4) Aprender nuevas habilidades (técnicas y cognitivas) para apoyar el pensamiento crítico en medicina y urología. ${ }^{2}$

La mejor manera de comenzar con este enfoque es tan pronto como lo permita el programa académico. Ofrecerá al urólogo junior una mejor producción académica para su hoja de vida.

Se deben establecer diferentes intervenciones antes de comenzar un tiempo de investigación protegido, por ejemplo: Identificación de áreas de interés, establecimiento de objetivos, identificación del tiempo disponible, exploración de los recursos y fortalezas de la institución, conocimiento de posibles mentores y colaboradores, formulación de un plan de investigación accesible. y la búsqueda de fondos nacionales e internacionales. $^{2}$

No hay datos precisos que sugieran cuánto tiempo protegido es adecuado. Muchas instituciones sugieren la regla 80:20, que representa el $80 \%$ del tiempo de investigación y el 20\% del tiempo clínico, docente y administrativo. ${ }^{6}$ Sin embargo, esto podría no cumplir con la capacitación quirúrgica y del mundo real en países en vía de desarrollo. Según la experiencia académica, sugeriría proteger alrededor del 20\% del tiempo de investigación. No obstante, esto tiene que ser validado.
Address for correspondence Herney Andrés García-Perdomo, $M D, M S c, E d D, P h D, F A C S$, Departamento de Cirugía / Urología. Escuela de Medicina. Universidad del Valle. Cali, Colombia

(e-mail: editorrevista@scu.org.co).
DOI https://doi.org/ $10.1055 / \mathrm{s}-0039-3402308$ ISSN 0120-789X. e ISSN 2027-0119.
Copyright ( $)$ 2019, Sociedad Colombiana License terms de Urología. Publicado por Thieme Revinter Publicações Ltda., Rio de Janeiro, Brazil. Todos los derechos reservados.

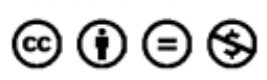


Como conclusión, la capacitación en una especialidad quirúrgica, especialmente en urología, debe pasar de centrarse únicamente en el cuidado de los pacientes, a tener un tiempo de investigación protegido con el fin de mejorar el liderazgo profesional en las carreras de los urólogos jóvenes y los resultados del paciente.

\section{Referencias}

1 Suliburk J, Kao L, Kozar R, Mercer D. Capacitación de futuros científicos quirúrgicos Realidades y recomendaciones. Ann Surg 2008;247:741-749

2 Singla N. El valor de proteger el tiempo de investigación durante el entrenamiento. Eur Urol 2019
3 Ko C, Whang E, Longmire W. Mejora de la participación del cirujano en la investigación: ¿es un problema de capacitación o prioridad? J Surg Res 2000;91:5

4 Mann M, Tendulkar A, Birger N, Howard C, Ratcliffe MB. National institutes of health funding for surgical research. Ann Surg 2008; 247(02):217-221

5 Thompson J. Semillas de maíz. Impacto de la atención administrada en la educación médica y la investigación. Ann Surg 1996;223:453-463

6 Barnard J. Tiempo protegido: un ingrediente vital para el desarrollo profesional de la investigación. JPGN 2015;60(03): 292-293 